\title{
ANALISIS KELEMBAGAAN DAN PERANAN KESATUAN PENGELOLAAN HUTAN PRODUKSI (KPHP) DALAM PENGEMBANGAN WILAYAH KABUPATEN KERINCI
}

\author{
Mika Lestaria, Setia Hadi, M. Buce Saleh \\ Program Studi Ilmu Perencanaan Wilayah \\ Sekolah Pascasarjana Institut Pertanian Bogor \\ Email : mika_foresta@yahoo.com
}

\begin{abstract}
Kerinci is one of regency with the large forest, but sub sector of forestry contributes only $0,04 \%$ of GDP Kerinci Regency. It's may possibly by the weakness of forest management and policy of Kerinci Regency Government. Forest production management unit (KPHP) Model Kerinci establishment is one of goverment efforts to achieve sustainable forest management. Therefore, we need research with purpose: (1) to analyze the role of forest production management unit (KPHP) Model Kerinci in the regional development of Kerinci Regency; (2) to analyze the institutional of forest production management unit (KPHP) Model Kerinci; (3) to analyze region's readiness forest production management unit (KPHP) Model Kerinci development. The study was conducted in Kerinci Regency. Data were analyzed by total economic value (TEV), institutional analysis, and analytical hierarchy process (AHP). The results showed that the total economic value of natural resources of KPHP Model Kerinci is Rp. 337.839.832.400 in a year, it's mean that sub sector of forestry potentially to contribute about 8,38\% of GDP Kerinci Regency. To realize the total economic values of natural resources of KPHP Model Kerinci, it needs strong institutions. Kerinci Regency is ready for KPHP Model Kerinci development, because it's has the support from stakeholders.
\end{abstract}

Keywords: Forest Production Management Unit (KPHP); Institutional Analysis; Total Economic Value (TEV).

\begin{abstract}
ABSTRAK
Kerinci merupakan salah satu kabupaten yang memiliki luasan hutan yang cukup tinggi, namun dari sub sektor kehutanan hanya berkontribusi sekitar 0,04 \% terhadap PDRB Kabupaten Kerinci. Hal ini dimungkinkan oleh adanya kelemahan dalam pengelolaan dan kebijakan kehutanan yang dilakukan oleh pemerintah Kabupaten Kerinci. Pembentukan Kesatuan Pengelolaan Hutan Produksi (KPHP) Model Kerinci adalah salah satu upaya pemerintah dalam mewujudkan pengelolaan hutan yang efisien dan lestari. Oleh karena itu, dibutuhkan penelitian yang bertujuan untuk: (1) menganalisis peranan KPHP Model Kerinci dalam pengembangan wilayah Kabupaten Kerinci; (2) menganalisis model kelembagaan KPHP Model Kerinci; dan (3) menganalisis kesiapan daerah dalam pembangunan KPHP Model Kerinci. Metode analisis data dilakukan dengan analisis Nilai Ekonomi Total (NET), analisis kelembagaan, dan analisis hirarki proses (AHP). Hasil penelitian menunujukkan bahwa nilai ekonomi sumberdaya hutan KPHP Model Kerinci adalah sebesar Rp. 337.839.832.400/tahun, yang berarti bahwa sub sektor kehutanan berpotensi menyumbang sekitar 8,38\% terhadap Produk Domestik Regional Bruto (PDRB) Kabupaten Kerinci. Untuk dapat merealisasikan nilai ekonomi tersebut, dibutuhkan penguatan kelembagaan. Kabupaten Kerinci siap untuk pembangunan KPHP Model Kerinci, hal ini dapat dilihat dari dukungan para pihak dalam proses pelaksanaan dan pembangunan KPHP Model Kerinci.
\end{abstract}

Kata Kunci: Analisis kelembagaan; Kesatuan Pengelolaan Hutan Produksi; Nilai Ekonomi Total (NET). 


\section{PENGANTAR}

Pengembangan wilayah merupakan rangkaian kegiatan yang meliputi banyak aspek yang saling berinteraksi satu sama lain. Pada dasarnya pengembangan wilayah bertujuan agar suatu wilayah dapat berkembang menuju tingkat perkembangan yang diinginkan yang dilaksanakan dengan cara pemanfaatan sumberdaya yang dimiliki dengan cara optimal dan adil, meningkatkan keserasian antar wilayah, keterpaduan antarsektor pembangunan dalam rangka mewujudkan pembangunan berkelanjutan.

Salah satu ciri suatu wilayah dikatakan berkembang adalah jika meningkatnya perekonomian suatu wilayah. Saat ini sumberdaya alam sangat berperan dalam meningkatkan perekonomian suatu wilayah. Salah satunya adalah sumberdaya hutan.

Kabupaten Kerinci merupakan salah satu wilayah yang memiliki luasan hutan yang cukup tinggi. Luasan kawasan hutan di Kabupaten Kerinci tahun 2012 meliputi hutan pelestarian alam 191.822 ha, hutan produksi 28.655 ha, hutan adat 1.820,11 ha dan hutan hak/milik 5.000 ha. Dari luas hutan yang dimiliki, seharusnya sektor Kehutanan dapat berkontribusi lebih besar terhadap total Produk Domestik Regional Bruto (PDRB) Kabupaten Kerinci. Namun, sampai tahun 2012, sub sektor kehutanan hanya berkontribusi sebesar 0,04 persen terhadap PDRB Kerinci. Hal ini diindikasikan disebabkan oleh belum teridentifikasinya nilai-nilai sumberdaya hutan Kabupaten Kerinci, serta lemahnya kelembagaan dan kebijakan pengelolaan hutan oleh Pemerintah Kabupaten Kerinci.

Dalam melaksanakan misi pengurusan hutan di era otonomi daerah, pemerintah pusat meluncurkan berbagai kebijakan yang diharapkan dapat mendorong terwujudnya kelestarian hutan dan kesejahteraan masyarakat, serta sekaligus mengakomodir tuntutan dan kepentingan pemerintah daerah. Salah satu kebijakan yang sedang dikembangkan adalah apa yang tertuang dalam PP No 6/2007 yakni Kesatuan Pengelolaan Hutan (KPH). Badan Planologi Departemen
Kehutanan (2006) menyatakan bahwa pembentukan KPH bertujuan untuk menyediakan wadah bagi terselenggaranya kegiatan pengelolaan hutan secara efisien dan lestari.

Seiring dengan ditetapkannya Peraturan Menteri Dalam Negeri Nomor 61 Tahun 2010 Tentang Pedoman Organisasi dan Tata Kerja Kesatuan Pengelolaan Hutan Lindung dan Kesatuan Pengelolaan Hutan Produksi di Daerah, maka pembentukan Organisasi Kesatuan Pengelolaan Hutan Produksi (KPHP), merupakan salah satu strategi penting dalam meningkatkan kinerja pemerintah daerah Kabupaten Kerinci dan optimalisasi pelayanan kepada masyarakat dalam pengelolaan hutan serta untuk mewujudkan pengelolaan hutan yang efisien dan lestari.

Data dari Badan Planologi Kementerian Kehutanan (2013), hingga akhir tahun 2014, Kementerian Kehutanan menargetkan penyelesaian $120 \mathrm{KPH}$ (Kesatuan Pengelolaan Hutan) model di beberapa wilayah di Indonesia. KPH model merupakan bentuk awal (embrio) dari KPH yang selanjutnya secara bertahap dapat berkembang menjadi KPH. Salah satu KPH Model yang menjadi target adalah KPH Model di Kabupaten Kerinci Provinsi Jambi. KPH Model Kerinci telah ditetapkan berdasarkan Surat Keputusan Menteri Kehutanan No. SK.960/ Menhut-II/2013 tentang Penetapan Wilayah Kesatuan Pengelolaan Hutan Produksi Model Kerinci (Unit I) yang terletak di Kabupaten Kerinci, Provinsi Jambi seluas \pm 34.250 (tiga puluh empat ribu dua ratus lima puluh) hektar.

Tujuan penelitian ini adalah menganalisis peranan KPHP Model Kerinci dalam pengembangan wilayah Kabupaten Kerinci, menganalisis model kelembagaan KPHP Model Kerinci dan menganalisis kesiapan daerah dalam pembangunan KPHP Model Kerinci.

Hasil dari penelitian ini diharapkan sebagai salah satu referensi dalam penelitian terkait Kesatuan Pengelolaan Hutan Produksi (KPHP). Selain itu dapat menjadi sumber informasi bagi Pemerintah 
Daerah Kabupaten Kerinci dalam rangka pembangunan di sektor kehutanan.

Penelitian dilaksanakan selama 7 (tujuh) bulan, yaitu pada bulan Mei 2014 sampai November 2014. Lokasi penelitian adalah KPHP Model Kerinci yang terletak di Kabupaten Kerinci Provinsi Jambi. KPHP model Kerinci dipilih sebagai lokasi penelitian karena KPHP ini merupakan KPHP model yang ditetapkan berdasarkan Surat
Keputusan Menteri Kehutanan Republik Indonesia No. SK.960/Menhut-II/2013 tentang Penetapan Wilayah Kesatuan Pengelolaan Hutan Produksi Model Kerinci (Unit I) yang terletak di Kabupaten Kerinci, Provinsi Jambi seluas \pm 34.250 (tiga puluh empat ribu dua ratus lima puluh) hektar. Lokasi wilayah KPHP Model Kerinci tersebar di 12 Kecamatan dari total 16 Kecamatan di Kabupaten Kerinci yang dapat dilihat pada Gambar 1.

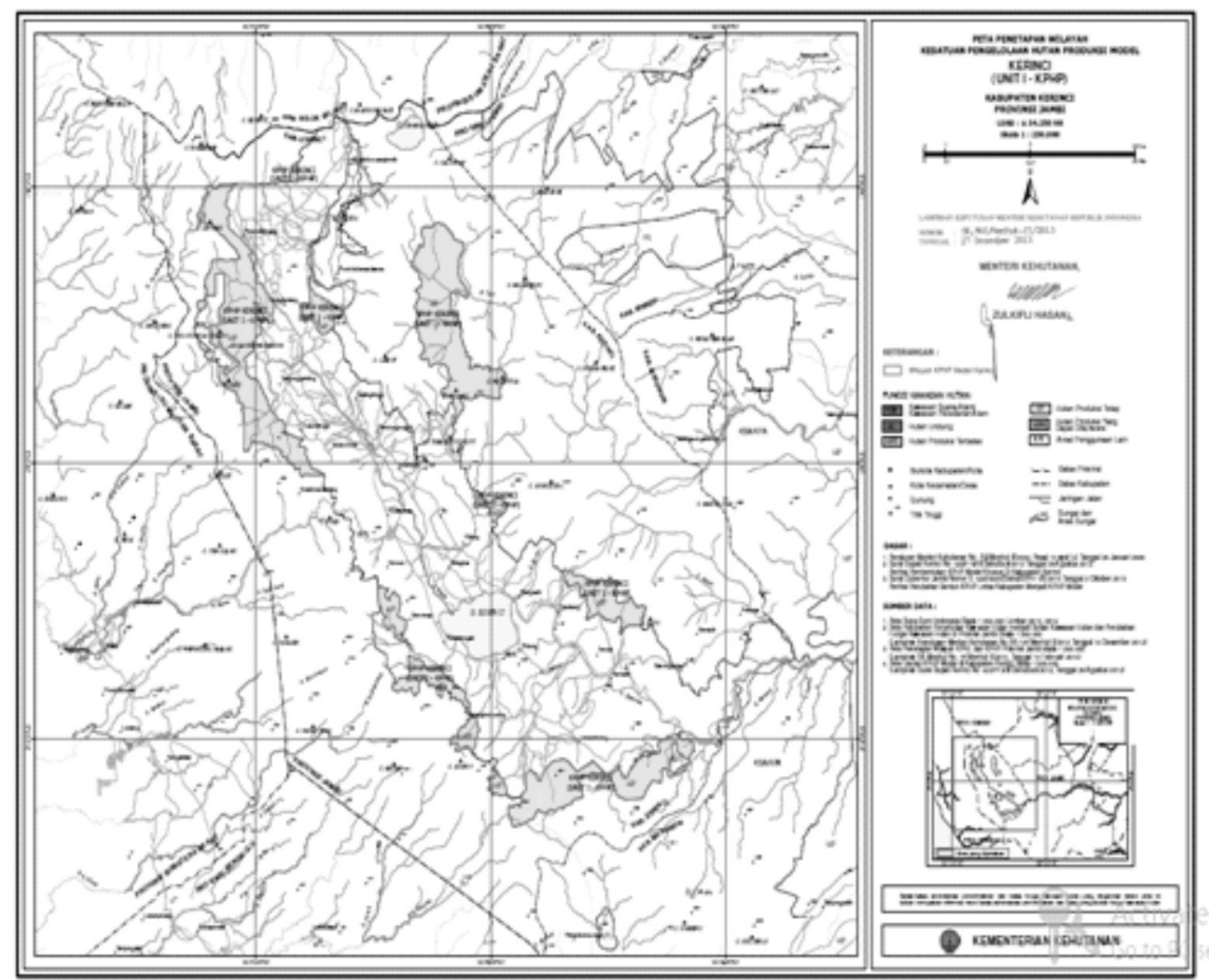

Gambar 1

Peta Penetapan KPHP Model Kerinci berdasarkan SK Menhut No.SK.960/Menhut-II/2013

Bahan yang digunakan dalam penelitian ini yaitu data PDRB Kabupaten Kerinci Tahun 2012; Rancang Bangun Pembentukan Kesatuan Pengelolaan Hutan Produksi (KPHP) dan Kesatuan Pengelolaan Hutan Lindung (KPHL) Provinsi Jambi; RT/ RW Kabupaten Kerinci Tahun 2012-2032; Peta RT/RW Kabupaten Kerinci; dan Peta Kawasan Hutan Kabupaten Kerinci. Alat yang digunakan yaitu kamera, blangko kuisioner, laptop dengan software ArcGis, dan MS Office.
Pengumpulan data dilakukan dengan teknik observasi kualitatif dan kuantitatif, wawancara dan studi dokumen. Pemilihan sampel dilakukan secara sengaja (purposive sampling).

\section{Analisis Nilai Ekonomi Total (NET)}

Analisis Nilai Ekonomi Total (NET) dalam penelitian ini digunakan untuk mengetahui peranan KPHP Model Kerinci dalam pengembangan wilayah Kabupaten 
Kerinci. Metode penilaian ekonomi yang digunakan yaitu metode penilaian berdasarkan harga pasar dan metode penilaian dengan willingness to pay (WTP).

Nilai Ekonomi Total yang digunakan dalam penelitian ini mengklasifikasikan nilai hutan sebagai berikut: Pertama, Nilai guna langsung (direct use values), yaitu nilai kayu bulat, agroforestry dan Kedua, Nilai guna tidak langsung (indirect use values), yaitu nilai jasa lingkungan sebagai pengatur tata air, penyerap karbon, pengatur iklim, pencegah erosi dan longsor, pencegah banjir, dan sebagai tempat wisata alam.

\section{Analisis Kelembagaan KPHP Model Kerinci}

Selama ini kelembagaan (institusi) banyak diartikan sebagai organisasi, namun sebenarnya juga mencakup ideologi, hukum, adat istiadat, aturan, kebiasaan yang tidak terlepas dari lingkungan. Menurut North (1990), secara umum kelembagaan mengandung dua pengertian penting yaitu: Pertama, kelembagaan diartikan sebagai aturan main (the rules of the game). Sebagai aturan main, kelembagaan berupa aturan baik formal maupun informal, yang tertulis dan tidak tertulis mengenai tata hubungan manusia. Kedua, kelembagaan sebagai suatu organisasi, ada beberapa stakeholder yang terlibat dalam pengelolaan sumberdaya termasuk hutan.

Pengelolaan sumberdaya hutan terdapat beberapa pemangku kepentingan (stakeholder). Stakeholders ini akan mempunyai kepentingan dan mewakili kelompoknya, baik dalam pemanfaatan maupun dalam pelestariannya. Apabila salah satu stakeholder tidak terlibat dalam pengelolaannya akan berdampak pada keberlanjutan pengelolaan kawasan hutan tersebut. Menurut Tadjudin (2000), identifikasi stakeholders yang terlibat dalam pengelolaan hutan antara lain: Pertama, stakeholders primer, yaitu pelaku yang terlibat (berkepentingan) langsung dalam kegiatan konservasi dan/atau pendayagunaan sumberdaya hutan: (1) pemerintah, yaitu instansi yang menangani pengelolaan sumberdaya hutan di daerah maupun di pusat; (2) swasta yang memiliki konsesi di kawasan yang bersangkutan; (3) masyarakat yang kegiatan ekonomi maupun kegiatan sosial-budayanya secara langsung tergantung pada sumberdaya hutan yang bersangkutan. Kelompok ini lazim disebut sebagai masyarakat pengguna. Kedua, stakeholders sekunder, meliputi: instansi pemerintah yang tidak bertanggungjawab langsung dalam hal pengelolaan sumberdaya hutan namn berkepentingan terhadap sumberdaya yang bersangkutan, misalnya swasta yang tidak terlibat dalam pengusahaan hutan, tetapi memiliki lini bisnis yang terkait dengan sumberdaya hutan atau terkait dengan kegiatan masyarakat yang kehidupannya tergantung pada sumberdaya hutan; masyarakat yang dipengaruhi oleh perubahan pengelolaan sumberdaya hutan sesudah manajemen kolaboratif diterapkan. Secara praktikal kelompok ini adalah masyarakat yang bermukim di sekitar hutan di luar batas yurisdiksi kawasaan hutan yang akan dikelola secara kolaboratif (Tadjudin 2000).

Analisis kelembagaan pada penelitian ini dilakukan secara deskriptif yang diarahkan untuk mendapatkan gambaran dan situasi daerah dalam pengelolaan KPHP Model Kerinci. Responden dipilih secara sengaja yaitu stakeholder dari Dinas Kehutanan dan Perkebunan Kabupaten Kerinci, Kementerian Kehutanan, Bappeda Kabupaten Kerinci, Dinas Pertanian Kabupaten Kerinci, LSM/ Pemerhati Lingkungan, Akademisi, dan Masyarakat.

\section{Analisis Persepsi Stakeholders}

Analisis persepsi stakeholders dilakukan dengan menggunakan metode Analitycal Hierarchy Process (AHP) untuk menggali persepsi stakeholders terkait kesiapan daerah dalam pembangunan KPHP Model Kerinci. Prinsip kerja AHP adalah penyederhanaan suatu persoalan yang kompleks dan tidak terstruktur, strategis dan dinamis serta menata dalam suatu hirarki. Kemudian tingkat kepentingan setiap variabel diberi 
numerik secara subyektif tentang arti penting variabel tersebut secara relatif dibanding dengan variabel yang lain. Dengan berbagai pertimbangan kemudian dilakukan sintesis untuk menetapkan variabel yang memiliki prioritas tinggi dan berperan untuk mempengaruhi hasil pada sistem tersebut (Marimin, 2004). Secara umum langkahlangkah yang dilakukan sebagai berikut: (1) mendefinisikan masalah dan menentukan solusi masalah, (2) membuat struktur hirarki, yang diawali dengan tujuan umum, dilanjutkan dengan sub-sub tujuan, kriteria dan kemungkinan alternatif-alternatif pada tingkatan kriteria yang paling bawah. Pendekatan AHP menggunakan skala banding berpasangan menurut Saaty (1993).

\section{HASIL DAN PEMBAHASAN Nilai Ekonomi Total Sumberdaya Hutan KPHP Model Kerinci Nilai Ekonomi Kayu}

Berdasarkan data dari Direktorat Jenderal Planologi Kementerian Kehutanan (Ditjenplan Kemenhut, 2014) bahwa total potensi kayu yang ada di KPHP Model Kerinci untuk areal berpenutupan primer adalah sebesar 1.621.526, $92 \mathrm{~m} 3$, sedangkan total potensi kayu untuk areal berpenutupan hutan sekunder adalah sebesar 58.795,45 $\mathrm{m} 3$. Jenis-jenis pohon yang mendominasi di areal KPHP Kerinci adalah medang, kelat, mempening dan meranti dengan sebaran kelas diameter pohon mulai dari $20 \mathrm{~cm}$ sampai dengan diameter diatas $80 \mathrm{~cm}$.

Penilaian ekonomi kayu yang dimaksud dalam penelitian ini adalah nilai ekonomi kayu pada areal yang boleh ditebang yaitu pada areal yang berpenutupan hutan sekunder dengan luas 510,88 ha dan potensi kayu sebesar 58.795,45 m3. Dari jumlah tersebut, potensi kayu jenis komersial sekitar $65,79 \mathrm{~m} 3 /$ ha. Diperoleh etat tebang 537,77 $\mathrm{m} 3 /$ tahun.

Nilai ekonomi kayu diperoleh dengan menghitung jumlah kayu yang boleh ditebang pertahun dikalikan dengan harga jualnya. Harga kayu di tegakan dihitung setelah dikurangi biaya operasional (biaya tebang dan biaya transportasi dari lokasi tebangan ke pabrik), maka didapatkan harga tegakan sebesar $\mathrm{Rp}$ 1.500.000/m3 untuk semua jenis kayu. Hal ini berdasarkan harga pasar lokal untuk tahun 2014 di daerah Kerinci khususnya. Maka nilai ekonomi kayu pada hutan sekunder adalah Rp806.655.000/ tahun.

\section{Nilai Ekonomi Agroforestry}

Keberadaan KPHP Model Kerinci memberikan manfaat dari agroforestry. Areal agroforestry ini berada pada penutupan lahan pertanian dan perkebunan seluas $24.713,61$ ha. Penilaian ekonomi agroforestry ini dilakukan dengan menghitung produksi rata-rata setiap komoditas per hektar per tahun. Komoditas yang ditanam di areal agroforestry KPHP Model Kerinci pada umumnya hampir sama. Jenis yang dominan yaitu kopi, kayu manis, surian, kemiri, cengkeh, alpukat, durian, sirih, cabe, tomat, pisang, bambu, kayu bakar, pinang. Diperoleh nilai agroforestry sebesar Rp. 12.235.000/ ha/tahun. Maka dari itu, total nilai ekonomi agroforestry untuk luasan 24.713,61 ha adalah sebesar Rp 302.371.018.400/tahun.

\section{Nilai Ekonomi Jasa Lingkungan}

Nilai ekonomi jasa lingkungan pada wilayah KPHP Model Kerinci diestimasi dengan menggunakan pendekatan analisis Willingness To Pay (WTP). Pendekatan WTP ini dilakukan dengan mewawancarai 60 responden yang tinggal di sekitar KPHP Model Kerinci dimana mereka diminta pendapatnya tentang kesediaan untuk melakukan pembayaran atas manfaat dari jasa lingkungan yang dirasakan oleh masyarakat terhadap keberadaan hutan pada KPHP Model Kerinci. Manfaat dari jasa lingkungan yang dimaksud seperti pengaturan tata air, penyerap karbon, pencegah erosi dan longsor, pencegah banjir, dan pengatur iklim.

WTP masyarakat yang merasakan manfaat dari sumberdaya hutan KPHP Model Kerinci cukup bervariasi, mulai dari Rp.5.000 sampai Rp.30.000 per bulan. Berdasarkan hasil perhitungan data WTP 
masyarakat, didapat bahwa total nilai WTP yang dikeluarkan responden adalah sebesar 735.000 per bulan dengan rata-rata WTP masyarakat adalah sebesar Rp12.250/bulan atau Rp147.000/tahun. Nilai ini terbilang cukup kecil dikarenakan sebagian besar penduduk yang tinggal di kawasan KPHP Model Kerinci memiiki pendapatan yang relatif rendah.

Nilai jasa lingkungan diperoleh diperoleh dengan mengalikan nilai WTP per tahun dengan jumlah populasi Kabupaten Kerinci, yaitu sebanyak 235.797 KK (Kerinci dalam angka 2012), maka Nilai Pilihan dari KPHP Model Kerinci adalah sebesar Rp.34.662.159.000/tahun.

Tabel 1

Nilai Ekonomi Total Sumberdaya Hutan pada KPHP Model Kerinci

\begin{tabular}{lll}
\hline No. & \multicolumn{1}{c}{ Jenis Manfaat } & $\begin{array}{c}\text { Nilai Ekonomi } \\
\text { (Rp/tahun) }\end{array}$ \\
\hline 1 & Nilai Guna Langsung & 806.655 .000 \\
& Nilai Kayu & \\
& Nilai Agroforestry & 302.371 .018 .400 \\
2 & Nilai Guna Tidak & 34.662 .159 .000 \\
& Langsung & \\
& Nilai Jasa Lingkungan & \\
\hline & Jumlah & 337.839 .832 .400 \\
\hline
\end{tabular}

Hasil analisis nilai ekonomi total sumberdaya hutan pada wilayah KPHP Model Kerinci, ternyata dari subsektor kehutanan berpotensi menyumbang sebesar Rp 337 Milyar/tahun artinya berpotensi menyumbang sebesar 8,38 \% terhadap PDRB Kabupaten Kerinci. Potensi kontribusi sebesar 8,38\% tersebut dianggap masih dalam bentuk PDRB Hijau karena di dalamnya terdapat nilai jasa lingkungan yang selama ini tidak diperhitungkan dalam PDRB (PDRB Coklat) Kabupaten Kerinci. Nilai yang diperhitungkan dalam PDRB Coklat Kabupaten Kerinci adalah nilai dari komoditas kehutanan seperti kayu, getah, rotan, bamboo, dan sebagainya yang dalam penelitian ini diambil dari nilai ekonomi kayu dan nilai ekonomi agroforestri. Oleh karena itu, dari nilai ekonomi total sebesar Rp 337 milyar/tahun tersebut yang berpotensi menyumbang terhadap PDRB tercatat (PDRB Coklat) adalah sebesar Rp303 milyar/tahun ( nilai ekonomi kayu dan nilai ekonomi agroforestri) atau sekitar 7,51\%. Hal ini jauh lebih besar dibandingkan dengan kontribusi sub sektor kehutanan terhadap PDRB Kabupaten Kerinci tahun 2012 yang tercatat (PDRB Coklat) sebesar Rp 1,7 Milyar atau sebesar 0,04\% dari total PDRB Kabupaten Kerinci Rp 4.03 Triliun.

\section{Kelembagaan KPHP Model Kerinci Stakeholders dalam Kelembagaan KPHP Model Kerinci}

Stakeholders yang terlibat dalam KPHP Model Kerinci secara umum dapat dikelompokkan menjadi dua, yaitu (1) stakeholders primer yang terdiri dari masyarakat, Dinas Kehutanan dan Perkebunan Kabupaten Kerinci dan Pemerintah Pusat (Kementerian Kehutanan); (2) stakeholders sekunder yang terdiri dari Bappeda Kabupaten Kerinci, Dinas Pertanian Kabupaten Kerinci, BBTNKS, BP2HP Wilayah IV Jambi, BPKH Wilayah XIII Pangkal Pinang, Akademisi, dan LSM pemerhati lingkungan.

Berdasarkan matrik tingkat kepentingan dan pengaruh terhadap para stakeholders, menunjukkan bahwa pihak yang paling berperan dalam pengelolaan KPHP Model Kerinci adalah Dinas Kehutanan dan Perkebunan Kab. Kerinci, Masyarakat sekitar hutan, dan Pemerintah Pusat (Kementerian Kehutanan) yang memiliki tingkat pengaruh yang tinggi. Yang berarti bahwa para stakeholders primer ini harus melakukan kerjasama dan koordinasi yang baik agar pelaksanaan pembangunan KPHP Model Kerinci dapat terwujud. Sedangkan dari Bappeda, Akademisi, Dinas Pertanian, LSM memiliki tingkat kepentingan yang rendah sampai tinggi.

\section{Kelembagaan KPHP Model Kerinci Saat ini}

Saat ini kelembagaan KPHP Model Kerinci masih berupa Unit Pelaksana Teknis Dinas (UPTD) di bawah Dinas Kehutanan dan Perkebunan Kabupaten Kerinci. Sesuai 
dengan Peraturan Menteri Dalam Negeri No. 61 tahun 2010 tentang Pedoman organisasi dan tata kerja KPHP dan KPHL di daerah bahwa bentuk organisasi KPH adalah berupa satuan kerja perangkat daerah (SKPD).

Struktur Organisasi UPTD KPHP Model Kerinci berdasarkan Peraturan Bupati Kerinci Nomor 14 Tahun 2013 seperti pada Gambar 2.

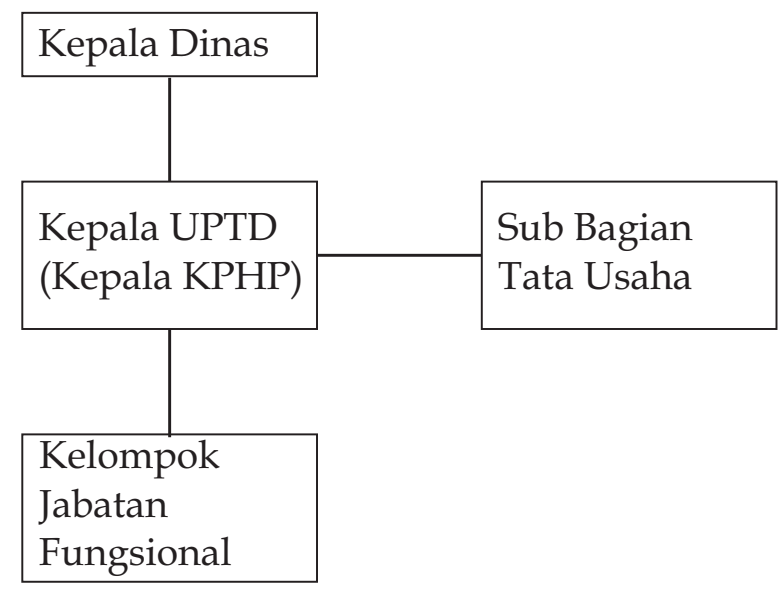

Gambar 2

Struktur Organisasi KPHP Model Kerinci

\section{Kelembagaan KPHP Model Kerinci berdasarkan Persepsi dan Harapan Stakeholders}

Model kelembagaan KPHP Model Kerinci berdasarkan persepsi dan harapan stakeholder bahwa KPHP Model Kerinci tetap menjadi UPTD Kabupaten sehingga amanat Permendagri Nomor 61 Tahun 2010 dapat terpenuhi. Dengan demikian UPTD KPHP Model Kerinci berada di bawah Kepala Dinas yang menangani kehutanan di Kabupaten Kerinci. KPHP menjalankan tugas mengelola hutan pada tingkat lapangan didukung oleh sumber daya manusia yang diangkat dan diberhentikan oleh Bupati.

Oleh karena itu, wilayah KPHP Model Kerinci tersebar di 13 Kecamatan, maka berdasarkan persepsi para pihak, perlu dibentuk beberapa resort pengelolaan di beberapa kecamatan agar memudahkan dalam pemantauan dan pengawasan di lapangan. Pada setiap resort akan satu orang terdapat kepala resort dan beberapa staf dengan jabatan fungsional. Pembentukan resort pengelolaan didasarkan pada pertimbangan kedekatan lokasi, sub DAS, dan luas kawasan. Adapun arahan pembagian resort pada KPHP Model Kerinci adalah sebagai berikut:

\section{Resort 1}

Resort 1 merupakan gabungan dari lokasi KPHP Model Kerinci yang berada di Kecamatan Gunung Tujuh, Kecamatan Kayu Aro, dan Kecamatan Kayu Aro Barat dengan luas resort diperkirakan sekitar 4.000 Ha. Jenis Penutupan lahan yang dominan pada resort ini adalah lahan pertanian dan perkebunan. Jenis penutupan lahan lainnya pada resort adalah tubuh air, penutupan hutan primer, hutan sekunder dan semak belukar. Oleh karena itu, jenis penutupan lahan yang dominan pada resort ini adalah lahan pertanian dan perkebunan, maka potensi Pemanfaatan lahan pada resort 1 ini diarahkan untuk pengembangan agroforestri kayu manis.

\section{Resort 2}

Resort 2 merupakan gabungan dari lokasi KPHP Model Kerinci yang berada di Kecamatan Gunung Kerinci dan Kecamatan Siulak dengan luasan diperkirakan sekitar $7.500 \mathrm{Ha}$. Resort ini merupakan resort paling luas dibandingkan dengan resort lainnya. Jenis Penutupan lahan yang dominan hampir sama dengan resort 1 yaitu lahan pertanian dan perkebunan. Penutupan lahan lain adalah hutan primer, hutan sekunder dan semak belukar. Oleh karena itu, jenis penutupan lahan pada resort ini yang dominan adalah berupa lahan pertanian dan perkebunan, maka pemanfaatan lahan diarahkan untuk pengembangan agroforestri kopi.

\section{Resort 3}

Resort 3 merupakan gabungan dari lokasi KPHP Model Kerinci yang berada di Kecamatan Siulak Mukai, Kecamatan Air Hangat, dan Kecamatan Air Hangat Timur 
dengan luasan diperkirakan sekitar 7.300 Ha. Jenis Penutupan lahan yang dominan hampir sama dengan resort 1 dan 2 yaitu lahan pertanian dan perkebunan. Penutupan lahan lain adalah hutan primer, hutan sekunder, semak belukar dan lahan terbuka. Pemanfaatan lahan pada resort ini diarahkan untuk pengembangan agroforestri kayu manis

\section{Resort 4}

Resort 4 merupakan gabungan dari lokasi KPHP Model Kerinci yang berada di Kecamatan Sitinjau Laut dan Kecamatan Keliling Danau dan Kecamatan Siulak dengan luasan diperkirakan sekitar 3.500 Ha. Resort ini merupakan resort yang memiliki luasan yang paling kecil di antara resort-resort lainnya. Jenis Penutupan lahan yang dominan, yaitu lahan pertanian dan perkebunan. Penutupan lahan lain adalah hutan primer, hutan sekunder dan semak belukar. Pemanfaatan lahan resort ini diarahkan untuk pengembangan agroforestri surian.

\section{Resort 5}

Resort 5 merupakan lokasi KPHP Model Kerinci yang berada di Kecamatan Batang Merangin dengan luasan diperkirakan sekitar 4.000 Ha. Jenis Penutupan lahan yang dominan, yaitu lahan pertanian dan perkebunan. Jenis penutupan lahan lain adalah hutan primer dan semak belukar. Resort ini merupakan resort yang memiliki luasan hutan primer paling tinggi di antara resort-resort lainnya. Pemanfaatan lahan diarahkan untuk perlindungan keanekaragaman hayati.

\section{Resort 6}

Resort 6 merupakan gabungan dari lokasi KPHP Model Kerinci yang berada di Kecamatan Bukit Kerman dan Kecamatan Gunung Raya dengan luasan diperkirakan sekitar 7.000 Ha. Jenis Penutupan lahan yang dominan hampir sama dengan resort-resort lainnya yaitu berupa lahan pertanian dan perkebunan. Penutupan lahan lain adalah hutan primer, hutan sekunder dan semak belukar.

Pemanfaatan lahan diarahkan untuk pengembangan agroforestri surian. Adanya arahan pembentukan resort-resort pengelolaan KPHP Model Kerinci ini, diharapkan dapat mempermudah dalam pengawasan wilayah KPHP karena akan terdapat petugaspetugas yang langsung berada di lapangan yang akan mengawasi wilayah KPHP, sehingga dapat mengurangi berbagai bentuk gangguan terhadap wilayah KPHP Model Kerinci, seperti perambahan, pembalakan liar, konflik tata batas, pendudukan kawasan hutan oleh pihak yang tidak bertanggung jawab, dan sebagainya.

\section{Kesiapan Daerah dalam Pembangunan KPHP Model Kerinci}

Kesiapan daerah yang dimaksud di sini, kesiapan dari para pihak yang tertarik dengan keberadaan KPHP Model Kerinci yang kemungkinan mendukung atau bertentangan/berlawanan dengan keberadaan KPHP Model Kerinci. Para pihak yang dimaksud adalah Dinas Kehutanan dan Perkebunan Kabupaten Kerinci, Bappeda Kabupaten Kerinci, Masyarakat sekitar lokasi KPHP Model Kerinci, para pemerhati lingkungan dan kehutanan (LSM/ akademisi), Dinas Kehutanan Provinsi Jambi, Balai Pemantapan Kawasan Hutan Wilayah XIII Pangkal Pinang, dan BP2HP wilayah IV Jambi.

Analisis kesiapan daerah dalam pelaksanaan KPHP Model Kerinci didasarkan pada persepsi para pihak yang terlibat. Metode yang digunakan dalam analisis ini adalah metode Analitycal Hierarchy Process (AHP). Struktur hirarki yang dibangun pada AHP dan hasil analisis dirumuskan dari persepsi para pihak yang dapat dilihat pada gambar 3 . 


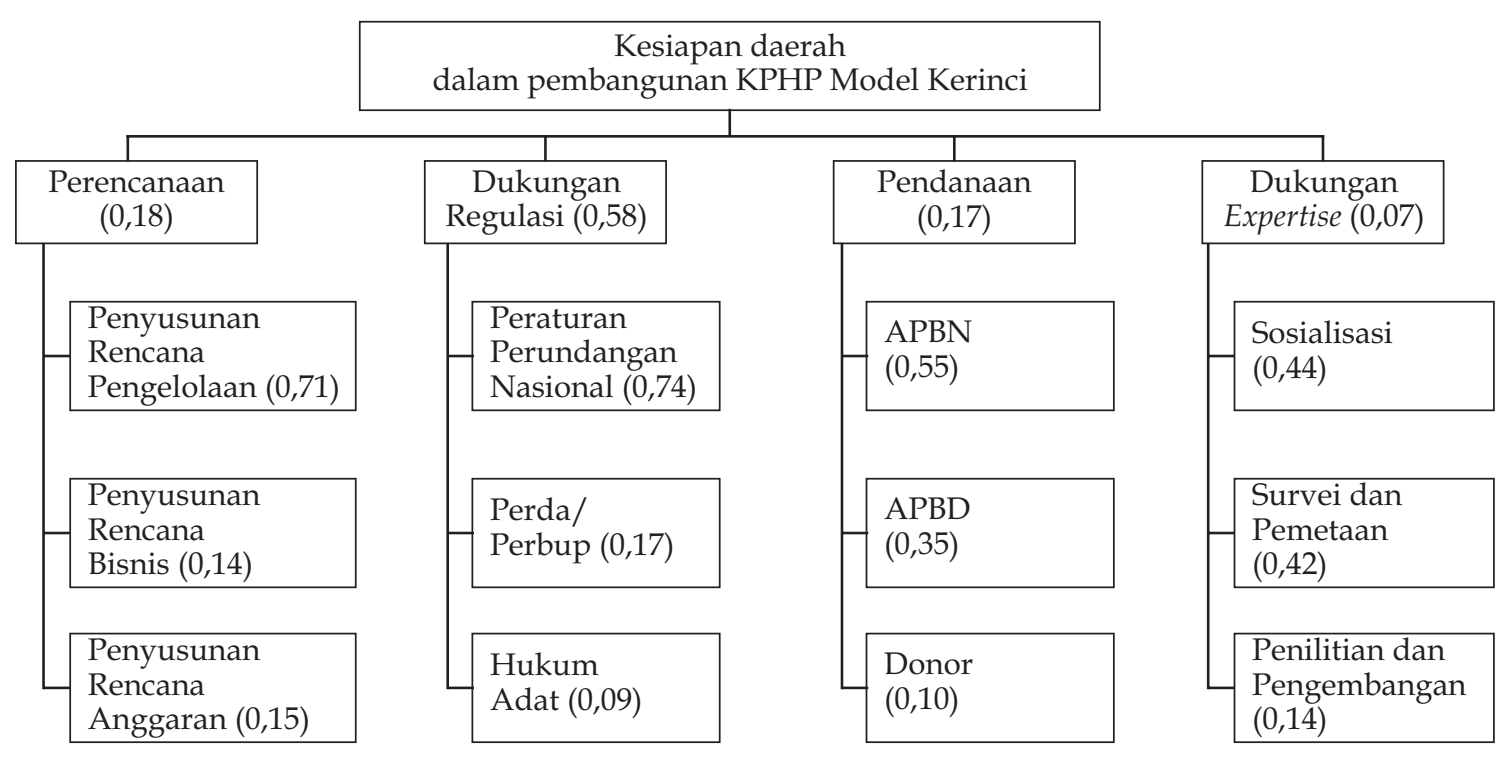

Gambar 3

Struktur Hirarki Kesiapan Daerah dalam Pembangunan KPHP Model Kerinci

\section{Dukungan Regulasi}

Dukungan regulasi dipilih sebagai prioritas pertama karena KPHP Model Kerinci merupakan hutan milik negara yang pengelolaan dan pemanfaatannya harus mengikuti ketentuan hukum yang berlaku. Dukungan regulasi merupakan pijakan dasar dan pedoman dalam melakukan pembangunan KPHP Model Kerinci.

Kesiapan daerah terkait dengan dukungan regulasi saat ini dapat dilihat dari persepsi para pihak di antaranya: (1) Dukungan Peraturan Perundangan Nasional terkait $\mathrm{KPH}$ sudah ada namun belum memadai; (2) Peraturan Bupati terkait KPHP Model Kerinci sudah ada, tetapi Peraturan Daerah belum ada; (3) Beberapa daerah di Kabupaten Kerinci yang berbatasan langsung dengan lokasi KPHP Model Kerinci tidak memiliki Hukum Adat terkait pemanfaatan dan pengelolaan hutan.

\section{Perencanaan}

Pembangunan KPHP Model Kerinci harus diselenggarakan melalui dukungan perencanaan yang baik, komprehensif dan melibatkan para pihak. Dari hasil persepsi para pihak diketahui bahwa Rencana Pengelolaan KPHP Model Kerinci telah disusun namun belum disahkan, rencana bisnis KPHP Model Kerinci belum disusun, Rencana Anggaran Kegiatan KPHP Model Kerinci tahun 2015 sudah ada dan sudah disahkan.

\section{Pendanaan}

Pembangunan KPHP Model Kerinci harus didukung dengan dana yang memadai agar semua kegiatan dapat terealisasi. Alokasi dana untuk pembangunan KPHP Model Kerinci sebagian besar bersumber dari APBN (sekitar 70\%), alokasi dana dari APBD masih belum memadai, saat ini tersedia juga dana dari donatur yaitu dari Flora Fauna Indonesia (FFI).

\section{Dukungan Expertise}

Dukungan expertise menjadi salah satu kriteria kesiapan daerah dalam pembangunan KPHP Model Kerinci karena menurut pendapat para pakar bahwa dukungan expertise sangat penting untuk membantu proses pembangunan KPHP Model Kerinci. Dukungan expertise yang dimaksud disini adalah dukungan berupa tenaga ahli yang diperbantukan dari para pihak untuk proses pelaksanaan pembangunan KPHP Model Kerinci. 
Sosialisasi pembangunan KPHP Model Kerinci belum dilakukan kepada seluruh instansi pemerintah dan non pemerintah terkait di Kerinci, survei dan pemetaan sudah pernah dilakukan di lokasi KPHP Model
Kerinci, belum ada kegiatan penelitian dan pengembangan terkait KPHP Model Kerinci. Adapun nilai dari kesiapan daerah dalam pembangunan KPHP Model Kerinci dapat dilihat pada Tabel 2.

Tabel 2

Penilaian Kesiapan Daerah dalam Pembangunan KPHP Model Kerinci

\begin{tabular}{|c|c|c|c|c|}
\hline No & Kriteria dan Indikator & Bobot & Nilai & Kesiapan Daerah \\
\hline \multirow[t]{4}{*}{1} & Perencanaan & & & \\
\hline & a. Penyusunan Rencana Pengelolaan & 0,118 & 0,568 & 0,067 \\
\hline & b. Penyusunan Rencana Bisnis & 0,024 & 0,093 & 0,002 \\
\hline & c. Penyusunan Rencana Anggaran & 0,025 & 0,876 & 0,022 \\
\hline \multirow[t]{4}{*}{2} & Dukungan Regulasi & & & \\
\hline & a. Peraturan Perundangan Nasional & 0,381 & 0,571 & 0,217 \\
\hline & b. Perda/Perbup & 0,083 & 0,397 & 0,033 \\
\hline & c. Hukum Adat & 0,046 & 0,284 & 0,013 \\
\hline \multirow[t]{4}{*}{3} & Pendanaan & & & \\
\hline & a. APBN & 0,118 & 0,593 & 0,070 \\
\hline & b. APBD & 0,076 & 0,523 & 0,040 \\
\hline & c. Donor & 0,020 & 0,453 & 0,009 \\
\hline \multirow[t]{6}{*}{4} & Dukungan Expertise & & & \\
\hline & a. Sosialisai & 0,049 & 0,715 & 0,035 \\
\hline & b. Survei dan Pemetaan & 0,046 & 1,000 & 0,046 \\
\hline & c. Penelitian dan Pengembangan & 0,015 & 0,130 & 0,002 \\
\hline & Jumlah & 1,000 & & 0,556 \\
\hline & Tingkat capaian & & & $55,6 \%$ \\
\hline
\end{tabular}

Tabel 3

Interval Tingkat Kesiapan Daerah dalam Pembangunan KPHP Model Kerinci

\begin{tabular}{|c|c|c|}
\hline No & Tingkat Kesiapan & Interval \\
\hline 1 & Sangat siap & $\geq 80$ \\
\hline 2 & Siap & $51-79$ \\
\hline 3 & Kurang siap & $21-50$ \\
\hline 4 & Tidak siap & $\leq 20$ \\
\hline
\end{tabular}

Hasil penilaian kesiapan daerah dalam pembangunan KPHP Model Kerinci sebesar 55,6\%, artinya bahwa Pemerintah Kabupaten Kerinci telah melaksanakan kriteria dan indikator kesiapan daerah dalam pembangunan KPHP Model Kerinci sebesar $55,6 \%$. Tingkat capaian ini memposisikan Pemerintah Kabupaten Kerinci berada pada tingkat capaian siap yaitu berada pada interval $51 \%$ sampai $75 \%$.

Indikator yang telah dilaksanakan dengan baik yaitu survei dan pemetaan. Indikator yang belum dipenuhi di antaranya:
(1) penyusunan rencana bisnis; (2) Penelitian dan pengembangan. Indikator yang telah dilaksanakan namun belum optimal di antaranya: (1) Penyusunan Rencana Pengelolaan; (2) Penyusunan Rencana Anggaran; (3) Peraturan Perundangan Nasional; (4) Perda/ Perbup; (5) Hukum Adat; (6) Pendanaan dari APBN; (7) Pendanaan dari APBD; (8) Pendanaan dari Donor; (9) Sosialisasi.

Pelaksanaan dalam tugas pengelolaan KPHP Model Kerinci dapat berjalan dengan baik efektif dan efisien, maka berdasarkan bobot masing-masing indikator pada tabel 
12, ada beberapa indikator yang harus segera dibenahi di antaranya: Pertama, Dukungan regulasi berupa ketersediaan Peraturan Perundangan Nasional yang memadai sehingga dapat dijadikan dasar dan landasan dalam pelaksanaan tugas pengelolaan KPHP di tingkat tapak. Kedua, Dukungan perencanaan berupa Percepatan pengesahan rencana pengelolaan KPHP Model Kerinci. Rencana Pengelolaan merupakan pedoman dan arahan dalam pelaksanaan pembangunan KPHP Model Kerinci untuk jangka waktu 10 tahun. Ketiga, Dukungan pendanaan berupa ketersediaan dana yang bersumber dari APBN harus ditingkatkan lagi demi kelancaran pelaksanaan tugas. Keempat, Penyusunan Peraturan Daerah terkait KPHP Model Kerinci. Kelima, Alokasi dana APBD masih sangat sedikit. Oleh karena itu Dana APBD untuk KPHP Model Kerinci perlu ditingkatkan. Mengingat KPHP Model Kerinci akan menjadi modal dalam pembangunan daerah Kerinci baik dari segi ekonomi, ekologi maupun sosial. Keenam, Sosialisasi pada seluruh pihak terkait KPHP Model Kerinci.

\section{SIMPULAN}

Keberadaan KPHP Model Kerinci berpotensi berperan dalam pengembangan wilayah Kabupaten Kerinci. Hal ini ditunjukkan dari Nilai Ekonomi Total Sumberdaya Hutan padaWilayah KPHP Model Kerinci sebesar Rp337 milyar/tahun. Dari nilai tersebut, berpotensi menyumbang terhadap PDRB tercatat (PDRB Coklat) adalah dari nilai ekonomi kayu dan nilai ekonomi agroforestri sebesar Rp303 milyar/tahun atau sekitar $7,51 \%$.

Untuk dapat merealisasikan nilai sumberdaya hutan pada simpulan di paragraf pertama, maka dibutuhkan kelembagaan ideal yang disesuaikan dengan kebutuhan daerah. Model Kelembagaan KPHP Model Kerinci perlu dikembangkan dengan pem- bentukan resort-resort pengelolaan pada beberapa Kecamatan. Ada enam resort pengelolaan yang dapat dibentuk berdasarkan pertimbangan luasan kawasan, kedekatan lokasi, dan potensi pemanfaatan lahan.

Kabupaten Kerinci sudah siap dalam pembangunan KPHP Model Kerinci. Hal ini terlihat dari tingkat capaian kesiapan daerah sebesar 55,6\%. Akan tetapi, ada beberapa indikator yang harus dibenahi terutama indikator pada kriteria dukungan regulasi dan perencanaan.

\section{DAFTAR PUSTAKA}

Badan Pusat Statistik Kabupaten Kerinci. 2013. Kabupaten Kerinci Dalam Angka Tahun 2013. Kerinci (ID): BPS Kabupaten Kerinci.

Direktorat Jenderal Planologi Kementerian Kehutanan. 2013. Laporan Inventarisasi Biogeofisik KPHP Model Kerinci. Jakarta (ID): Kementerian Kehutanan.

Kementerian Kehutanan. 2014. Rencana Pengelolaan Hutan: KPHP Model Kerinci. Pangkal Pinang (ID): BPKH wilayah XIII Pangkal Pinang, Direktorat Jenderal Planologi Kehutanan, Kementerian Kehutanan.Marimin. 2004. Teknik dan Aplikasi Pengambilan Keputusan Kriteria Majemuk. Jakarta (ID) : Grasindo. PT Gramedia Widiasarana Indonesia.

North, D.C. 1990. Institutions, institutional change and economic performance. Cambridge University Press. New York.

Saaty TL. 1993. Pengambilan Keputusan bagi Para Pemimpin. Terjemahan. Jakarta (ID): PT. Pustaka Binaman Presindo.

Tadjudin, D. 2000. Manajemen kolaboratif. Pustaka Latin. Bogor. 